\title{
Amino-Functionalized Alkylsilane SAM-Assisted Patterning of Poly(3-hexylthiophene) Nanofilm Robustly Adhered to $\mathrm{SiO}_{2}$ Substrate
}

\author{
Ilsun Pang, Jin-Hyo Boo, ${ }^{\dagger}$ Honglae Sohn, ${ }^{\ddagger}$ Sungsoo Kim, and Jaegab Lee \\ Center for Materials and Processes of Self-Assembly. School of Athanced Haterials Engineering, Kookmin Lniversity, \\ Seoul 136-702, Korea. ${ }^{\circ}$ E-mail: surforceakookminac.kr \\ ${ }^{\dagger}$ Department of Chemistry, Sunghynkwan Lniversity, Suw on $+40-7+6$, Korea \\ -Department of Chemistry, Chosun Lniversity, Gwangit 501-759, Korea \\ Received March 25, 2008
}

\begin{abstract}
We report a novel patterning method for a homo-polymeric poly(3-hexỵlthiophene) (P3HT) nanofilm particularly capable of strong adhesion to $\mathrm{SiO}_{2}$ surface. An oxidized silicon wafer substrate was micro-contact printed with $n$-octadecyltrichlorosilane (OTS) monolayer. and subsequently its negative pattern was selfassembled with three different amino-functionalized alkylsilanes. (3-aminopropyl)trimethoxy silane (APS). $\mathrm{N}$ (2-aminoethyl)-3-aminopropyltrimethoxy silane (EDAS). and (3-trimethoxy silylpropyl) diethylenetriamine (DETAS). Then. P3HT nanofilms were selectively grown on the aminosilane pre-pattemed areas via the vapor phase polymerization method. To evaluate the adhesion, patterning, and the film itself. the PEDOT nanofilms and SAMs were investigated with a Scotch ${ }^{\bar{B}}$ tape test. contact angle analyzer. ATR-FT-IR, and optical and atomic force microscopes. The evaluation showed that the newly developed all bottom-up process can offer a simple and inexpensive patterning method for P3HT nanofilms robustly adhered to an oxidized \$i wafer surface by the mediation of $\mathrm{FeCl}_{3}$ and amino-functionalized alkṇlsilane SAMs
\end{abstract}

Key Words : Poly(3-hexylthiophene), Amino-alkylsilane, Patteming. Vapor phase polymerization

\section{Introduction}

For decades conductive $\pi$-conjugated polymers have fascinated many scientists since these substances have great potential for applicability to next-generation optoelectronic devices such as organic thin film transistors (OTFTs) and organic light emitting diodes (OLEDs). ${ }^{l}$ Among these polymers poly(3-hexylthiophene) (P3HT) has received particular attention as an active layer or p-type transport layer of OTFT and OLED devices. ${ }^{3}$ Due to good solubility of P3HT in non-polar organic solvents. it can be easily prepared as a thin film using wet processes such as spin-coating and recrystallization. These methods are typically employed for integrating an active layer into an OTFT device. However. P3HT has not been very popular as electrode materials mainly due to unavailability of a good dopant as well as effective doping method. To overcome this drawback. a dry film-forming process of P3HT. i.e., a vapor phase polymerization (VPP) method ${ }^{4.5}$ could be a good choice for effective doping. In the VPP method. monomers of a conducting polymer in a closed chamber can be vaporized simply via temperature elevation. and these molecules can be quickly self-assembled and easily polymerized on an oxidizing agent (as well as a dopant)-coated substrate. thereby producing a homo-polymer thin film. Via this method our laboratory very recently demonstrated that a highly effectively $\mathrm{FeCl}_{3}$ doped $(\sim 600 \mathrm{~S} / \mathrm{cm})$ poly (3.4-ethylenediosythiophene) (PEDOT) nanofilm can be prepared as an electrode materials. ${ }^{67}$ Therefore it is reasonable to believe that the VPP method could also offer an effectively doped P3HT electrode for an OTFT device
Nonetheless. the application of a P3HT film to a conventional TFT fabrication process still has a couple of technical hurdles. too. They are the poor adhesion of the P3HT thin film to the oxide substrate and the lack of a scalable and inexpensive patterning method. Patterning of wet-processed P3HT films has typically depended on traditional and well-established subtractive tecliniques such as photolithography. which is expensive and complex. As an effort to resolve these problems. our laboratory recently developed an all bottom-up patterning process via the combination of a self-assembly techuique and VPP method. ${ }^{6.7}$ In this method. various amino-functionalized alkylsilane monolayers were self-assembled on the negative patterns of micro-contact printed OTS monolayers. Then. PEDOT nanofilms were selectively grown on the anino-functionalized alkỵlsilane monolayer via the VPP method. The films were characterized and it was discovered that the PEDOT nanofilms can be very effectively patterned on and that they robustly adhered to the oxide substrate most likely through direct chemical bonding. Therefore in this work. we have also tried to prepare a highly effectively doped and selectively patterned P3HT nanofilm particularly capable of strong adhesion to $\mathrm{SiO}_{2}$ surface via the combination of an alkỵlsilane self-assembly technique and VPP method.

\section{Experimental Details}

The main chemicals used in this study were 3HT (3hexylthiophene. 99\%. Aldrich. St. Louis. USA). OTS (nOctadecyltrichlorosilane. 99\%. Aldrich. St. Louis. USA). APS (3-Aminopropyl)trimethoxỵsilane, 97\%. Aldrich Inc. 
St. Louis. USA), EDAS (N-[2-Aminoethyl]-3-aminopropy]trimethoxysilane, 97\%. Gelest Inc. USA), and DETS (3Trimethoxysily lpropyl)diethylenetriamine, 97\%, Gelest lnc. USA). All other chemicals and solvents were reagent grades ( $96-99 \%$ purity) and used as received.

The oxidized (100) Si wafer $(1.5 \mathrm{~cm} \times 1.5 \mathrm{~cm})$ was soaked into a piranha solution for ten minutes and then rinsed with ultra-pure water to remove any organic contaminants that may adsorbed on the sufface. A PDMS stamp was used for microcontact printing to transfer OTS SAM patterns onto the wafer substrate. thereby rendering the stamped area hydrophobic (water contact angle $=\sim 110^{\circ}$ ). After the OTS printing, the negative pattern was coated with aninofunctionalized alkylsilane monolayers (APS, EDAS, and DETS) by dipping it into the silane solution $(0.1 \mathrm{mM}$ silane $+\mathrm{l} \mu \mathrm{M}$ acetic acid in $50 \mathrm{ml}$ ethyl alcohol) for at least an hour. After rinsing it with ethyl alcohol and subsequent drying via $\mathrm{N}$ : blowing. $3(\mathrm{w} / \mathrm{v}) \% \mathrm{FeCl}_{3}$ was spread onto the monolayer surface and spun at $2500 \mathrm{rpm}$ with a spin coater for 90 seconds. The mixed monolayer sample coated with the $\mathrm{FeCl}_{3}$ catalyst (dopant) was placed in a mechanical circulation oven (Yuyu Scientific Mfg. Co. Korea) including $3 \mathrm{HT}$. The $3 \mathrm{HT}$ was vaporized for thirty minutes at $55^{\circ} \mathrm{C}$ and inmediately polymerized. Then, the polymer was selectively patterned on a Si wafer surface to form a P3HT film. The sample was always rinsed with methanol and then dried in a desiccator prior to the characterization.

All optical microscopic inages in this study were taken with a PME 3 (Olympus. Japan) at room temperature and in an ambient atmosphere, and a magnification of 50 times was used. Static water contact angles were measured with a goniometer (Phoenix 300, Surface Electro Optics Co. Ltd.. Korea) and recorded with a CCD camera. A grazing incidence Attenuated Total Reflection-Fourier Transforn Infrared (ATR-FT-IR) microspectrometer (Hyperion 3000, Bruker Optics Inc., Germany) was used to detect organic functional groups of P3HT film and aminosilane SAM. The ATR objective (a $45^{\circ}$ polarized beam in the IR mode: magnification $=20 \mathrm{x}$ : resolution $=4 \mathrm{~cm}^{-1}$, scan time $=64$ times) used for the IR measurements is surface-sensitive enough to detect a functional group in a film as thin as $\sim 50 \mathrm{~nm}$. To measure a sheet resistance for the conductivity calculation. a four point probe (CMT-series. Changmin Co. Ltd.. Korea) was used. All atomic force microscopic images were measured with a SPA 400 (Seiko. Japan: tapping mode. scan speed: $0.5 \mathrm{~Hz}$, scan size: $30 \times 30 \mu \mathrm{m})$. To evaluate the adhesion between the $\mathrm{P} 3 \mathrm{HT}$ film and the $\mathrm{SiO}_{2}$ surface. a $3 \mathrm{M}$ Scotch $^{\mathbb{E}}$ tape test was carried out.

\section{Results and Discussion}

Static water contact angles on tluree different amino-functionalized propyltrimethoxysilane SAMs were measured and compared with previously reported values. The measured contact angles were $21^{\circ} .25^{\circ}$, and $39^{\circ}$ for APS. EDAS, and DETAS monolayers. respectively. These values are fairly close to the previously reported ones of $22^{\circ}, 28^{\circ}$, and $41^{\circ}$ for APS $^{\circ}$, EDAS $^{\circ}$, and DETAS ${ }^{111}$ SAMs, respectively. In addition, to confirm the monolayer fomation. X-ray photoelectron spectroscopic data were collected from the blanketdeposited amino-functionalized alkylsilane ultrathin films on a $\mathrm{SiO}_{2}$ surface. $\mathrm{C}$ Is and $\mathrm{N}$ ls peaks were commonly observed from all of the three films and the intensities of $\mathrm{N}$ Is were in excellent agreement with the amounts of $\mathrm{N}$ ls electrons escaped from the monolayers as reported in our previous publications. ${ }^{6.7}$ These obviously support that the amino-functionalized silane molecules form a smooth monolayer film.

To evaluate the adhesion between the P3HT nanofilm and the $\mathrm{SiO}_{2}$ surface. amino-functionalized alkylsilane (APS, EDAS. DETAS) monolayers were blanket-deposited on an oxidized $\mathrm{Si}$ wafer surface. and then immediately rinsed with methanol. To directly observe the adhesion improvement, a Scotch ${ }^{\mathbb{E}}$ tape test was carried out and the results are shown in Figure 1. The images show the tapes detached from perpendicularly scratched P3HT films. These images obviously indicate that. unlike the $\mathrm{P} 3 \mathrm{HT}$ film on a bare $\mathrm{SiO}_{2}$ surface, the same film on amino-functionalized silane monolayers are not lifted off by tape at all. This result is very similar with the one from the PEDOT nanofilms grown on an APS SAM by VPP method. ${ }^{6}$ This clearly indicates that the aminofunctionalized silane monolayers play a critical role in improving adhesion between the P3HT film and $\mathrm{SiO}_{2}$ surface. most likely through direct chemical bonding.

Figure 2 shows atomic force microscopic images of P3HT nanofilms line-pattened $(\sim 6.5 \mu \mathrm{m}$ width) on amino-functionalized alkylsilane SAMs. These 3-dimensional images clearly indicate that P3HT nanofilms can be selectively deposited on the line pattens of amino-functionalized alkyisilane SAMs. In particular, the sharp edges and smooth lines

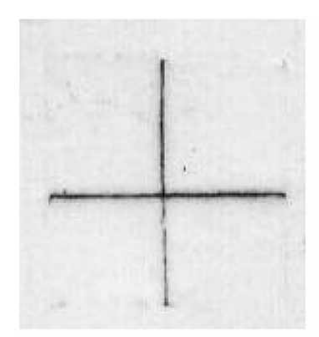

P3HT/APS

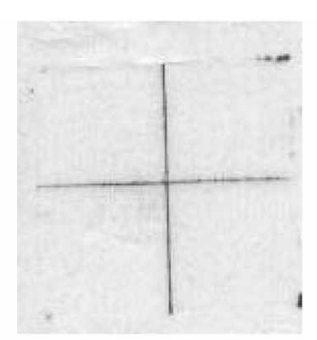

P3HT/DETAS

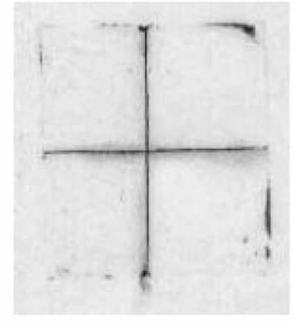

P3HT/EDAS

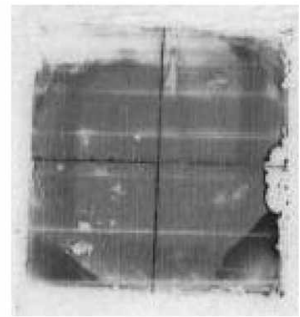

$\mathrm{P} 3 \mathrm{HT} /$ bare $\mathrm{SiO}_{2}$

Figure 1. An adhesion test carried out in this study. Optical microscopic images of Scoch" tapes detached from various P3HT/aminoalkylsilane SAM surfaces. Please, note a P3HT tilnn nearly completely comes off a bare SiOz surface. 


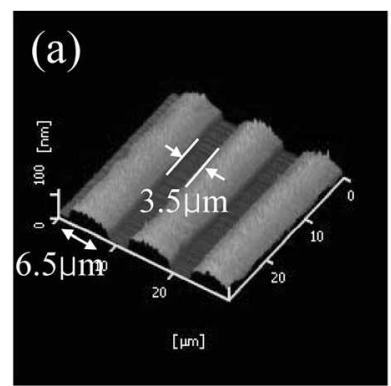

(a) P3HT/APS

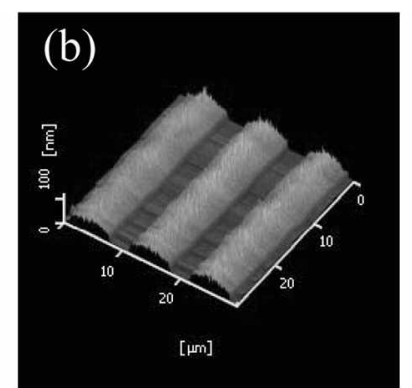

(b) P3HT/DETAS

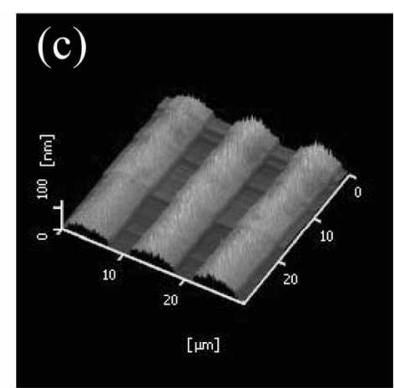

(c) P3HT/EDAS

Figure 2. Atomic force microscopic images of P3HT nanofilms selectively pattemed on amino-functionalized alkvisilane/OTS mixed SAMs.

of P3HT patterns shown in all of the inages visually confirm that the 3 HT monomers have an outstanding selectivity for aminosilane SAM over OTS-SAM. This selectivity obviously originates from the selective and uniform wetting of a $\mathrm{FeCl}_{3}$-dissolved solution on a hydrophilic aminosilane SAM surface. ${ }^{\circ}$ However. the highly acidic $\mathrm{FeCl}_{3}$ solution $(\mathrm{pH}=\sim 1.0)$ does not wet a completely hydrophobic OTSSAM surface at all. As a result, the $3 \mathrm{HT}$ monomers can polymerize and subsequently grow only on the $\mathrm{FeCl}_{3}$-coated aninosilane SAM patterns. In fact, the polymerization of 3HT monomers was identified by an ATR-FT-IR Spectrometer (Hyperion 3000, Bruker Optics Inc.. Germany). For example, the spectrum of a $\mathrm{FeCl}_{3}$-doped $\mathrm{P} 3 \mathrm{HT}$ complex on an APS SAM surface (Fig. 3) shows characteristic stretching vibrational bands due to conjugated $C=C\left(-1500 \mathrm{~cm}^{-1}\right)$ and disappearance of stretching bands $\left(3116 \mathrm{~cm}^{-1}\right)$ due to 2,5 . hydrogens of thiophene rings, firmly supporting that the monomers were polymerized. Another undeniable evidence for the polymerization is conductivity $(s)$ values for the P3HT films. The conductivity was calculated using the equation $\sigma=I S \cdot V d$. where $I . S, V$ and $d$ are an electrical current. applied voltage. area of cross-section of sample. and gap between electrodes, respectively. Table I shows conductivity values for $3 \mathrm{wt} \% \mathrm{FeCl}_{3}$-doped P3HT nanofilms on APS. EDAS. and DETAS SAMs. As shown, the conductivity values range from $0.49 \mathrm{~S} / \mathrm{cm}$ to $0.55 \mathrm{~S} / \mathrm{cm}$. These values well match with the one $(0.47 \mathrm{~S} / \mathrm{cm})$ measured from a solvent-casted crystalline P3HT film (2 wt \% FeCl $\mathrm{w}_{3}$-doped, $110 \mu \mathrm{m}$ thick film $).{ }^{11}$ This obviously supports that the P3HT nanofilms were indeed polymerized.

Another important issue for P3HT electrodes is the conductivity. itself. Around $0.5 \mathrm{~S} / \mathrm{cm}$ of the conductivity $(\sigma)$ values for vapor phase polymerized P3HT films is still far

Table 1. Conductivity of P3HT films

\begin{tabular}{lccc}
\hline P3HT $\left(\mathrm{FeCl}_{3}\right.$ dopant $)$ & $\begin{array}{c}\text { Film } \\
\text { thichness }\end{array}$ & $\begin{array}{c}\text { Conductivity } \\
(\mathrm{S} / \mathrm{cm})\end{array}$ & Ref. \\
\hline Solvent cast $\left(2 \mathrm{w} \% \mathrm{FeCl}_{3}\right)$ & $110, \mathrm{~mm}$ & 0.47 & {$[11]$} \\
Solvent cast $\left(19 \mathrm{wt} \% \mathrm{FeCl}_{3}\right)$ & $15, \mathrm{~mm}$ & $2.8 \times 10^{-3}$ & {$[12]$} \\
VPP on APS $\left(3 \mathrm{wt} \% \mathrm{FeCl}_{3}\right)$ & $\mathbf{5 2} \mathrm{nm}$ & $\mathbf{0 . 4 8 7}$ & \\
VPP on EDAS $\left(3 w \mathrm{t} \% \mathrm{FeCl}_{3}\right)$ & $\mathbf{5 5} \mathrm{nm}$ & $\mathbf{0 . 5 2 4}$ & \\
VPP on DETAS $\left(3 \mathrm{wt} \% \mathrm{FeCl}_{3}\right)$ & $\mathbf{5 3} \mathrm{nm}$ & $\mathbf{0 . 5 4 9}$ & \\
\hline
\end{tabular}

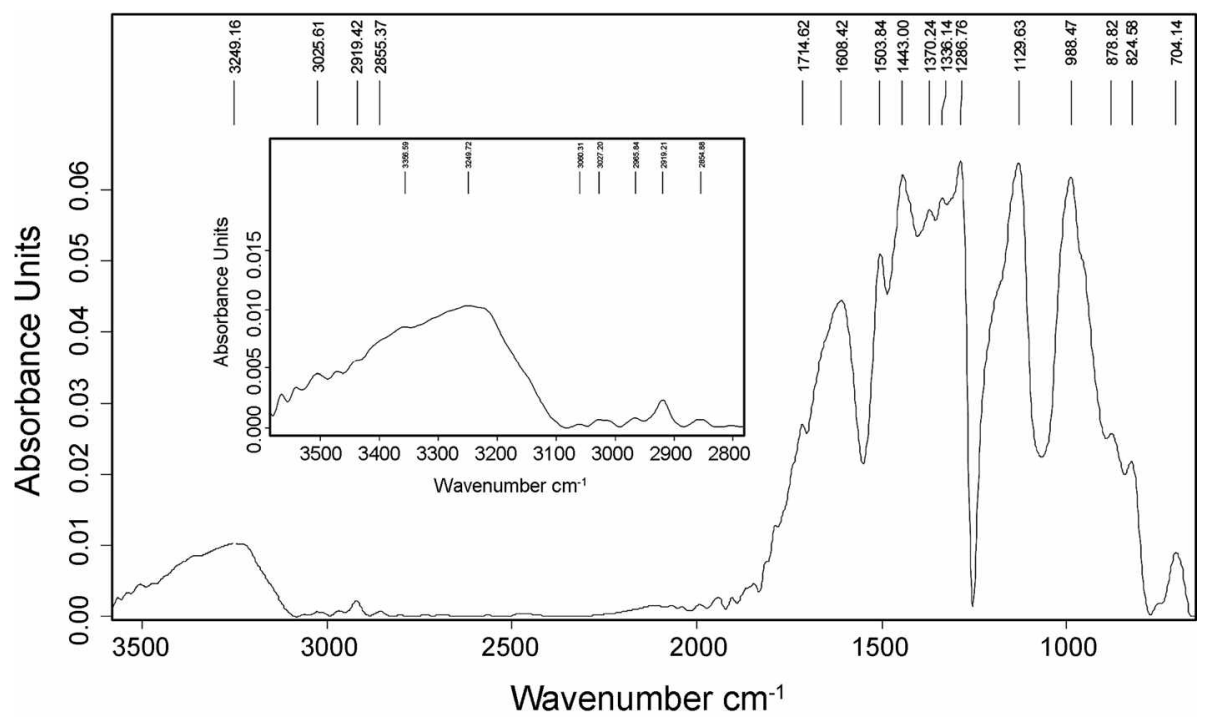

Figure 3. ATR-FT-IR spectrum of a P3HT nanotilm on a FeCl 3 -coated APS-SAM surface. Please note that the broad stretching vibrational band at $\sim 3200 \mathrm{~cm}^{-1}$ is due to hydrogen-bonded N-H groups on APS monolayer and the bands from $1300 \mathrm{~cm}^{-1}$ to $1500 \mathrm{~cm}^{-1}$ originate from conjugated $\mathrm{C}=\mathrm{C}$ stretching vibration. This clearly indicates that the $\mathrm{FeCl}_{3}$-doped film is a highly conjugated homo-polymer. The inset shows a magnified region for $\mathrm{N}-\mathrm{H}$ and $\mathrm{C}-\mathrm{H}$ stretching bands $\left(2800-3600 \mathrm{~cm}^{-1}\right)$. 
below the minimum value $(-50 \mathrm{~S} / \mathrm{cm})$ required for a reliable organic electrode materials. This issue was foreknown by a couple of indications ascertained from the polymerization time and morphology of $\mathrm{P} 3 \mathrm{HT}$ films. To reach nearly a 50 num thick film. P3HT film was grown for 30 minutes via the VPP method. This polymerization time is roughly 20 times slower than the one ( 3 minutes for $\sim 100 \mathrm{~nm}$ thick film) for the PEDOT growth by the same method. ${ }^{6.7}$ Such sluggish growth time of P3HT films means a low reactivity of $3 \mathrm{HT}$ molecules for the polymerization. Therefore, it is reasonable to conjecture that the polymerization does not proceed at large scale as the PEDOT does. In fact. the AFM images in Figure 2 show that the patterned P3HT morphology is not smooth after methanol washing which means that partly polymerized or only oligomerized tiny fragments easily come off the film surface. This phenomenon apparently supports the low reactivity of $3 \mathrm{HT}$ molecules upon polymerizing. and more importantly it at least in part explains why the P3HT films are not as conductive as the PEDOT films $(500-600 \mathrm{~S} / \mathrm{cm})$. Nevertheless. better or comparable conductivity values $(\sim 0.5 \mathrm{~S} / \mathrm{cm})$ measured from much thimuer VPP P3HT films $(-50 \mathrm{~nm})$ than solvent-casted crystalline P3HT films ${ }^{11.12}$ (Table 1) mean that the current much more effectively and quickly flows in parallel with the VPP film surface than with the thick solvent-casted films. This is a very desirable characteristic for the electrode materials of a TFT device where the current must run well through the electrode in parallel with the substrate surface. This evidently demonstrates that the VPP method is an excellent choice for effective doping. However, we were not able to pinpoint exactly why the wash-off happens at the monent and it is beyond the scope of the present study. Therefore, the P3HT growth mechanism needs to be elucidated in more detail for improving the quality of $\mathrm{P} 3 \mathrm{HT}$ electrode materials and it is currently underway.

\section{Conclusion}

This study successfully demonstrated that a P3HT nanofilm can be highly selectively and funely pattemed on an oxidized silicon wafer surface and strongly adhered to the substrate surface via the combination of a SAM teclunique and VPP method. In particular, it must be noted that this newly developed all bottom-up process could be a convenient and inexpensive patteming method for $\mathrm{P} 3 \mathrm{HT}$ nanofilms. and this significantly heightens the possibility a highly effectively doped $\mathrm{P} 3 \mathrm{HT}$ film can be employed as an electrode component of an OTFT device.

Acknowledgments. This work was supported by the Korea Science and Engineering Foundation (KOSEF) grant funded by the Korea government (MEST) (R11-2005-048-00000-0).

\section{References}

1. Nalwa. H. S. Handbook of Conductive Molecules and Polyners, Wiley: New York. 1997: Vols. 1-4.

2. Patzer. M. T.: Frisbie. C. D. Ach: Funt. Hater: 2006. J6. 1051

3. Dodabalapur. A.: Bao. Z.: Makhija. A.: Laquindanum. I. G.: Raju. V. R.: Feng. Y.: Katz, H. E.: Rogers. J. Appl. Plys. Lett 1998. 73. 142 .

4. Winther-Jensen. B.; West. K. Macromolecules 2004. 37, 4538.

5. Kim. J.: Kim. E.: Won, Y.: Lee. H.: Suh. K. Synth Het 2003, 139. 485.

6. Kim. S.: Pang. I.: Lee T. Macromol. Rapid Conmm 2007. 28. 1574

7. Pan1g. I.: Kiml. S.: Lee. T. Surf. Cout. Technol. 2007. 201.9426.

8. Petri, D. F. S.; Wenz. G.: Schunk. P.: Schimmel. T. Lamgmir 1999. 15,4520 .

9. Charles. P. T: Vora. G. J: Andreadis. J. D: Fortney, A. J.: Meador. C. E.: Dulcey. C. S.: Stenger. D. A. Langntuir 2003. 19. 1586.

10. Das. M.: Molnar. P.: Devaraj. H.: Poeta. M.: Hickman. T. I. Biotechnol Prog. 2003. 19. 1756.

11. Shiga. T: Okada, A. J. Appl. Polymer Sci. 1996, 62,903.

12. Singh, R. K.: Kumar, J: Singh, R.: Kant. R.: Rastogi, R. C.; Chand. S.: Kumar, V. Kew d. Phus. 2006, 8, 112. 